\title{
Double-Blind Cross-Over Placebo Controlled Study of Flunarizine in Patients With Therapy Resistant Epilepsy
}

\author{
E. Starreveld, F. de Beukelaar, A.F. Wilson, D.R. McLean and Helen P. Findlay
}

\begin{abstract}
Twenty-five patients with long-standing therapy resistant epilepsy were studied in an eight-month double-blind cross-over add-on trial with a daily dose of $15 \mathrm{mg}$ flunarizine. In five patients the seizure frequency decreased $50 \%$ or more. The mean seizure frequency reduction in the patients on flunarizine was $35 \%$. Particularly the control of secondary generalized seizures improved. Flunarizine did not significantly alter the plasma levels of the regular anticonvulsant drugs. Minimal adverse side effects were reported equally in the flunarizine and the placebo group. In three patients depressive symptoms improved and two patients became free of postictal headaches. Flunarizine appears to be a safe adjuvant anticonvulsant.
\end{abstract}

RÉSUMÉ: Étude croisée, contrôlée et à double inconnue, de l'efficacité de la flunarizine chez des patients présentant une épilepsie résistante au traitement Vingt cinq patients souffrant d'épilepsie résistant depuis longtemps au traitement ont été inclus dans une étude croisée à double insu d'une durée de 8 mois, au cours de laquelle ils ont reçu une dose quotidienne de $15 \mathrm{mg}$ de flunarizine outre les médicaments habituels. Chez 5 patients, la fréquence des crises a diminué de $50 \%$ ou plus. La réduction moyenne de la fréquence des crises chez les patients sous flunarizine s'élevait à $35 \%$. C'est dans les cas de crises secondaires généralisées que l'amélioration a été la plus marquée. La flunarizine n'a pas modifié significativement les taux plasmatiques des médicaments antiépileptiques habituels. Des effets secondaires minimes ont été rapportés tant dans le groupe flunarizine que dans le groupe placebo. Chez 3 patients, les symptômes dépressifs ont été atténués et 2 patients ont été débarrassés de leurs céphalées post-critiques. La flunarizine s'avère un adjuvant anticonvulsif sûr.

Can. J. Neurol. Sci. 1989; 16:187-190

Flunarizine hydrochloride, a difluoroderivative of cinnarizine, is the only known selective $\mathrm{Ca}^{2+}$-entry blocker that passes the blood-brain-barrier readily. ${ }^{1}$ Flunarizine has an anticonvulsant effect in the maximal pentylenetetrazole test in rats and the maximal electroshock test in mice. ${ }^{2}$ It antagonizes clonic seizures in amygdaloid kindled rats $^{3}$ and $\operatorname{dog} s^{4}$ and is active against the allylglycine induced seizures in rats. ${ }^{5}$ It has been suggested that flunarizine decreases burst-firing by acting on $\mathrm{Na}^{+}$and $\mathrm{Ca}^{2+}$ channels. ${ }^{6}$ There is histological evidence of normalization of the calcium distribution in hypoxic brain tissue, when flunarizine is administered. ${ }^{7}$

Flunarizine exerts a membrane stabilizing effect on arterial smooth muscle cells. ${ }^{8,9,10}$ In accordance flunarizine has been found to be effective in the prophylaxis of migraine, ${ }^{11,12,13}$ cerebrovascular disorders, 14 labyrinthine disease ${ }^{15}$ and alternating hemiplegia in childhood. 16,17

Flunarizine is completely absorbed in the stomach and has widespread distribution, with preferential storage in fatty tissues. Tissue levels are several times higher than plasma levels.
Steady state plasma levels remain constant during prolonged treatment with $10 \mathrm{mg}$ flunarizine per day. No accumulation, hepatic induction or self-induction have been demonstrated. The terminal half-life of flunarizine is $18.3 \pm 8.5$ days.

In clinical studies improved seizure control was reported in an add-on trial 18 and in a double-blind placebo controlled crossover trial with $10 \mathrm{mg}$ flunarizine as a daily add-on therapy. 19 Flunarizine was found to be most effective in a daily dosage of $15-20 \mathrm{mg}$ in an open dose ranging trial. ${ }^{20} \mathrm{We}$ report the results of a double-blind placebo controlled cross-over study with $15 \mathrm{mg}$ flunarizine daily as add-on therapy in 25 patients with therapy resistant epilepsy.

\section{Methods}

\section{Patients}

A total of 34 patients, 21 female and 13 male, from the Adult Convulsive Disorder Clinic at the Glenrose Hospital in Edmonton were selected on the following criteria: age 15-60

From the Adult Convulsive Disorder Clinic, Glenrose Rehabilitation Hospital, Edmonton (E.S., A.F.W., D.R.M.); Janssen Research Foundation, Beerse, Belgium (F. dB., H.P.F.)

Received October 21, 1988. Accepted in final form March 9, 1989

Reprint requests to: E. Starreveld, M.D., Adult Convulsive Disorder Clinic, Glenrose Rehabilitation Hospital, 10230 - 111 Avenue, Edmonton, Alberta, Canada T5G 0B7 
years, easily recognizable seizures with a frequency of at least four per month, taking not more than two anti-epileptic drugs and with repeated serum trough levels within the therapeutic range. All patients had been attending the clinic for at least one year and had four or more seizures per month during that period.

\section{Protocol}

The study consisted of three phases: a baseline phase of two months, a flunarizine phase of four months and a placebo phase of four months. During the baseline phase the patients underwent a general and neurological examination and laboratory tests including $\mathrm{CBC}$, differential, liver function tests, serum trough levels of the antiepileptic drugs (AED), EEG and urinalysis. Seizure documentation was reviewed with patients, relatives or group home workers. During the second phase, three placebo capsules or three $5 \mathrm{mg}$ capsules of flunarizine were administered as a single evening dose. The identity of the medications was known only to the dispensing pharmacist. After two months the patients were interviewed regarding seizure frequency and symptoms. Laboratory tests (except EEG) and AED blood levels were repeated. Compliance with the trial medication was observed by counting of the unused returned capsules. At the end of the second phase the same procedures and an EEG were repeated and the medication was switched from placebo to flunarizine or flunarizine to placebo.

During the third phase the patients were assessed as in phase two.

Seizures were documented by the patients as major (generalized convulsive seizures) or minor (partial or non-convulsive seizures). Halfway between clinic visits, patients were contacted by telephone regarding their progress.

\section{Laboratory Tests}

Routine laboratory tests and serum trough levels of the baseline anticonvulsants were done by the same laboratory. Plasma samples for serum levels of flunarizine were deep frozen and analyzed after the trial by Janssen Research Foundation Laboratories in Beerse, Belgium.

\section{Statistical Analysis}

The efficacy evaluation is based on the daily seizure frequency during the placebo and flunarizine phase. For every patient the change in major and minor seizures was calculated. However, a patient was considered to benefit more when major seizures were controlled compared to minor seizures. Hence major seizures were given precedence. For example, if a patient had more than four major seizures monthly, only the change in this seizure type was taken into account in determining if the patient was a responder or not.

The data were analyzed by Koch's non-parametric method for the two-period cross-over design.21

\section{RESULTS}

Nine patients, seven female and two male could not be evaluated. For one of the males there was incomplete documentation during the pre-trial phase and another male, age 19 , drowned during a bath as a result of a seizure. This patient was in phase II and proved to be on placebo.

Of the seven female patients, one had fewer than four seizures per month during the pre-trial phase. This patient has continued taking flunarizine outside the study and has remained seizure free for one year. One patient's phenytoin levels became subtherapeutic, one patient did not take the prescribed number of flunarizine capsules and one patient missed several review appointments. Three patients were hospitalized for uncontrolled seizures and had their regular anticonvulsant medication altered. Of these three patients, two were on placebo during phase II while the third was admitted during the baseline phase.

The remaining 25 patients, 11 male and 14 female, continued to fulfill all criteria and completed the study. Their age ranged from 17-47 years (mean: 32). The age of onset of seizures ranged from 0-42 years (mean: 10 ).

Eight patients had partial seizures only, one patient had secondary generalized seizures and 16 patients had partial and secondary generalized seizures.

Twenty-one patients were taking carbamazepine, 15 patients phenytoin, six patients valproate, two patients mesantoin, two patients primidone and one patient ethosuximide. Only three patients were on monotherapy and 22 patients were on two anticonvulsants.

In 11 patients the etiology of the epilepsy was unknown, 14 patients presented with abnormal neurological findings, including mental retardation, hemiparesis, hemianopsia or a history of encephalitis, brain concussion or intracerebral bleed before the onset of their seizures.

The mean seizure frequency during placebo therapy was 0.432 per day $(S D \pm 0.86)$ and during flunarizine therapy 0.308 per day ( $\mathrm{SD} \pm 0.70$ ), which is $35 \%$ lower. The Koch cross-over analysis shows an almost significant $(\mathrm{p}=0.055)$ treatment effect, in the absence of any period effect $(p=0.528)$ or carry-over effect $(\mathrm{p}=0.913)$.

Table 1 shows the response to flunarizine and placebo. Five patients had a $50 \%$ or more reduction of major or minor seizures during flunarizine treatment. None showed a similar reduction while on placebo. Six patients had a $25-49 \%$ reduction of their seizures during flunarizine treatment while two patients had a similar reduction while on placebo. The remaining 12 patients showed fluctuations of their seizure incidence below the $25 \%$ level. Of the five patients with a $50 \%$ or more response four were in the flunarizine-placebo sequence and one in the placebo-flunarizine sequence. Of the eight patients with only partial seizures none had a seizure reduction of $50 \%$ or more. One patient with only secondary generalized seizures had a $50 \%$ response. Four out of the 16 remaining patients with both seizure types also had a $50 \%$ response.

Table 2 summarizes the five patients with a seizure reduction of $50 \%$ or more. One patient had only secondary generalized seizures and four patients had partial and secondary generalized seizures. All four patients showed a marked reduction in their

Table 1: Effect of Flunarizine and Placebo on Seizure Frequency

\begin{tabular}{ccc}
$\begin{array}{c}\text { \% Decrease } \\
\text { Seizure Frequency }\end{array}$ & FLUNARIZINE & PLACEBO \\
\hline 250 & No. Patients & No. Patients \\
$25-49$ & 5 & - \\
$0-24$ & 6 & 2 \\
\end{tabular}


secondary generalized seizures. Two patients had also a marked reduction of their partial seizures. Three patients had a clinical neurologic deficit and all five patients were taking two conventional AED during the study.

The mean flunarizine level of the five responders was $37 \mathrm{ng} / \mathrm{ml}$ and the nonresponders was $36.6 \mathrm{ng} / \mathrm{ml}$. The AED levels during the three phases of the study are listed in Table 3. Flunarizine did not alter the AED levels significantly. Two patients, one responder and one nonresponder, who were taking Mesantoin (Mephenytoin), showed a decrease in the serum levels of this drug during the flunarizine phase. Minimal adverse side effects such as drowsiness, headaches, vertigo, change in appetite and weight were experienced equally in the flunarizine and placebo group. Depressive symptoms improved in three of four patients with a history of depression. Two patients reported spontaneously that they were free of postictal headaches while on flunarizine. None of the EEGs showed improvement in paroxysmal or background activity.

\section{Discussion}

Our study confirms the results of others. ${ }^{20} \mathrm{~A}$ daily dose of $15 \mathrm{mg}$ flunarizine reduced the mean seizure incidence by $35 \%$. It is striking that all responders had secondary generalized seizures whereas patients with only partial seizures did not respond. We did not observe a specific reduction of aura symptoms as has been reported. 20,21

Our patients experienced no significant side effects. Drowsiness, weight gain and dizziness were seen equally in the placebo and flunarizine group. The five flunarizine responders did not report any adverse effects. Flunarizine side effects reported in the literature are drowsiness, weight gain, mood changes and memory impairment. These side effects become prominent when flunarizine is given in a daily dosage of $15 \mathrm{mg}$ or more, especially when flunarizine is given as monotherapy. 20 When flunarizine is given as co-medication, the patients tolerate a higher dosage of flunarizine because the flunarizine serum levels remain lower than anticipated. This is probably the result of hepatic induction by the other AED's. There is no direct correlation between flunarizine serum levels and seizure control when the daily dosage ranges from $10-20 \mathrm{mg} / \mathrm{day} .{ }^{19,20} \mathrm{In}$ the individual patient repeated flunarizine serum levels are not a necessity because of the long half life of the drug and its stable pharmacokinetics. Flunarizine does not influence the levels of the conventional AED's, ${ }^{19,20}$ with a possible exception for mephenytoin, since in two patients lower levels were found.

Theoretically it might have been preferable to have a long washout period of three weeks or more between the flunarizine phase and placebo phase. We have not done this in order to facilitate patient compliance. Furthermore the Koch's analysis did not show any carry over effect.

Because of the long half life of flunarizine, even when comedication is given, longer trial and washout periods as well as adjustment of the flunarizine dosage guided by serum levels deserve consideration in future trials.

Three patients reported improvement of depressive symptoms. Contrary to reports in the literature, no adverse psychological effects occurred. ${ }^{23}$ Improvement in alertness and mood have been reported in non-depressed patients. 24 Two patients became free of postictal headaches. This mechanism is probably similar to the prophylactic effect of flunarizine in migraine.

Flunarizine is a useful adjuvant in the management of therapy resistant secondary generalized seizures. It has a number of advantages when compared to other "second choice" anticonvulsants. Further trials with larger numbers of patients will have

Table 2: Analysis of the 5 Patients With Seizure Reduction of $50 \%$ or More

\begin{tabular}{|c|c|c|c|c|c|c|}
\hline Patient No. & Age & Sex & $\begin{array}{l}\text { Partial Seizures } \\
\% \text { Improved }\end{array}$ & $\begin{array}{c}\text { Sec. Generalized Seizures } \\
\% \text { Improved }\end{array}$ & $\begin{array}{l}\text { Duration Epilepsy } \\
\text { Years }\end{array}$ & Neurological History \\
\hline 3 & 27 & $\mathrm{~F}$ & $50 \%$ & $100 \%$ & 25 & - \\
\hline 15 & 31 & M & $26 \%$ & $80 \%$ & 13 & - \\
\hline 25 & 27 & $\mathbf{M}$ & - & $91 \%$ & 25 & Measles Encephalitis \\
\hline 27 & 32 & $\mathrm{~F}$ & $83 \%$ & $80 \%$ & 22 & Porencephalic Cyst \\
\hline
\end{tabular}

Table 3: Serum Concentrations of Antiepileptic Drugs

\begin{tabular}{|c|c|c|c|c|c|c|c|}
\hline \multirow{3}{*}{ AED } & \multirow{3}{*}{$\mathbf{N}$} & \multirow{2}{*}{\multicolumn{2}{|c|}{ DOSE (mg/day) }} & \multirow{2}{*}{\multicolumn{4}{|c|}{\begin{tabular}{cr}
\multicolumn{2}{c}{ SERUM CONCENTRATIONS $(\mathrm{mMol} / \mathrm{ml})$} \\
Flunarizine Phase & Placebo Phase
\end{tabular}}} \\
\hline & & & & & & & \\
\hline & & Mean & Range & Mean & Range & Mean & Range \\
\hline Phenytoin & 15 & 326 & $(125-600)$ & $\mathbf{7 0 . 3 3}$ & $(7.5-109.5)$ & 64.83 & $(9.5-108.5)$ \\
\hline Valproic Acid & 5 & 1600 & $(250-3000)$ & 326.5 & $(35-574)$ & 374.7 & $(40-701)$ \\
\hline Divalproex Sodium & 1 & 1500 & & 388 & & 468 & \\
\hline Mephenytoin & 2 & 350 & $(200-500)$ & 9.5 & $(3.5-15.9)$ & 52.5 & $(19.1-86)$ \\
\hline
\end{tabular}


to be conducted to determine if flunarizine deserves a place as a first line antiepileptic drug.

\section{ACKNOWLEDGEMENTS}

We would like to thank the patients for participating in this study, and gratefully acknowledge the invaluable assistance of the staff of the seizure clinic: Jeanette Popowich R.N., Vicky Philip R.N., Eleanor Ball, secretary, and Mr. B. Parks, Pharmacist. A special thanks for Leigh-Ann Miller and Michele Marani who typed the manuscript. The Janssen Research Foundation supplied the trial medication, designed the protocol and analyzed the flunarizine serum levels.

\section{REFERENCES}

1. Michiels M, Hendriks A, Knaeps F, et al. Absorption and tissue distribution of flunarizine in rats, pigs and dogs. ArzneimittelForsch 1983; 33: 1135-1142.

2. Desmedt CKC, Niemegeers CJE, Janssen PAJ. Anticonvulsant properties of cinnarizine and flunarizine in rats and mice. Arzneimittel-Forsch 1975; 25: 1408-1413.

3. Ashton D, Wauquier A. Behavioral analysis of the effects of 15 anticonvulsants in the amygdaloid kindled rat. Psychopharm (Berlin) 1979a; 65: 7-13.

4. Wauquier A, Ashton D, Melis W. Behavioral analysis of amygdaloid kindling in beagle dogs and the effects of clonazepam, diazepam, phenobarbital, diphenylhydantoin and flunarizine on the seizure manifestation. Exp Neurol 1979; 64: 579-586.

5. Ashton D, Wauquier A. Effects of some antiepileptic, neuroleptic and gabaminergic drugs on convulsions induced in rats by injection of D,L-allylglycine. Pharm Biochem Behav 1979b; 11: 221226.

6. Ashton D, Marrannes R, Pauwels PJ, et al. Possible mechanisms of flunarizine's anticonvulsant activity. In: Vanden Bussche G, Wauquier A, Schmidt D, Meinardi H, eds. Proc. Int. Workshop on Flunarizine in Epilepsy: Health Science Review 1985; 45-59.

7. Meldrum B, Griffiths T, Evans M. Hypoxia and neuronal hyperexcitability: a clue to mechanisms of brain protection. In: Wauquier A, Borgers M, Amery WK, eds. Protection of Tissue Against Hypoxia. Amsterdam: Elsevier Biomedical Press 1982; 276.

8. Amery WK, Wauquier A, Van Nueten JM, et al. The antimigrainous pharmacology of flunarizine (R 14950), a calcium-antagonist. Drugs Exp Clin Res 1981; 7: 1-10.

9. Van Nueten JM, Van Beek J, Janssen PAJ. Effect of flunarizine on calcium-induced responses of peripheral vascular smooth muscle. Arch Int Pharmacodyn Ther 1978; 232: 42-52.
10. Van Nueten JM, Vanhoutte PM. Improvement of tissue perfusion with inhibitors of calcium influx. Biochem Pharmacol 1980; 29: 479.

11. Louis P. A double-blind placebo controlled prophylactic study of flunarizine (Sibelium) in migraine. Headache 1981; 21: 235239.

12. Diamond S, Schenbaum H. Flunarizine, a calcium channel blocker, in the prophylaxis of migraine. Headache $1983 ; 23: 39-42$.

13. Amery WK, Caeri LI, Aerts TJL. Flunarizine, a calcium entry blocker in migraine prophylaxis. Headache 1985; 25: 249-254.

14. Domschky K, Nelson M, Dammhayn B, et al. Flunarizine in patients with insufficient cerebral and peripheral blood flow - a multicentre double-blind study. Med West 1977; 28: 1062-1064.

15. Oosterveld WJ. Flunarizine in vertigo. A double-blind placebo controlled cross-over evaluation of a constant-dose schedule. ORL 1982; 44: 72-80.

16. Casaer $P$, Azou $M$. Flunarizine in alternating hemiplegia in childhood. Lancet 1984; 2 : 579.

17. Andermann F, Silver K, Hilaire MHS, et al. Paroxysmal alternating hemiplegia of childhood: treatment with flunarizine and other agents. Neurology 1986; 36 (Suppl 1): 327.

18. Declerck AC, Wauquier A. Double-blind study of the effectiveness of flunarizine in therapy-resistant epilepsy in mentally retarded children [Abstract]. Proceedings of the 11th Epilepsy International Symposium. Vancouver: Epilepsy International $1978 ; 169$.

19. Overweg J, Binnie CD, Meijer JWA, et al. Double-blind placebocontrolled trial of flunarizine as add-on therapy in epilepsy. Epilepsia 1984; 25(2): 217-222.

20. Binnie CD, de Beukelaar F. Meijer JWA, et al. Open dose-ranging trial of flunarizine as add-on therapy in epilepsy. Epilepsia $1985 ; 26(5): 424-428$

21. Koch GG. The use of non-parametric methods in the statistical analysis of the two-period change-over design. Biometrics 1972; 28: $577-584$.

22. Overweg J, Ashton D, de Beukelaar F, et al. Add-on therapy in epilepsy with calcium entry blockers. Eur Neurol 1986; 25: (Suppl 1): 93-101.

23. Chouza C, Caamaro JL, Aljanati R, et al. Parkinsonism, tardive dyskinesia, akathisia and depression induced by flunarizine. Lancet 1986, June 7: 1303-1304.

24. Heinze B, Karrass W, Peters Th. Pharmacopsychological effects of flunarizine in geriatric patients with light brain organic psychosyndrome. Eur Neurol 1986; 25: SI: 115-121. 